\title{
USO DE CLORAÇÃO E AR COMPRIMIDO NO CONTROLE DO ENTUPIMENTO DE GOTEJADORES OCASIONADO PELA APLICAÇÃO DE ÁGUA RESIDUÁRIA ${ }^{1}$
}

\author{
DENIS C. CARARO' ${ }^{2}$ TARLEI A. BOTREL ${ }^{3}$
}

\begin{abstract}
RESUMO: O crescimento demográfico, o aumento da demanda por água e alimentos, a crescente geração de resíduos, a poluição de corpos de água e a escassez de água têm ocasionado a busca por soluções, das quais uma é o aproveitamento do efluente de estações de tratamento de esgoto na agricultura. Um modo seguro de efetuar a aplicação desse recurso, também fertilizante, é utilizando a irrigação por gotejamento, porém o entupimento nesse sistema consiste em fator restritivo. Assim, com o objetivo de minimizar o entupimento em quatro modelos de gotejadores por uso de águas residuárias oriundas de tratamento secundário de estação de tratamento de esgoto, testaramse quatro tipos de manejo: (I) controle (somente filtragem), (II) cloração, (III) ar comprimido e (IV) cloração e ar comprimido. Obteve-se melhor resultado com o tratamento de $0,5 \mathrm{mg} \mathrm{L}^{-1}$ de cloro residual livre combinado ao gotejador autocompensante.
\end{abstract}

PALAVRAS-CHAVE: irrigação localizada, entupimento de emissores, efluente.

\section{CHLORINATION AND COMPRESSED AIR TO CONTROL THE WASTEWATER CLOGGING IN DRIPPERS}

\begin{abstract}
Population, water and food demand, waste and water pollution increasing are the reasons for wastewater reuse in agriculture by drip irrigation systems. However, the clogging is a restrictive fact in these systems, so prevention techniques are necessary to avoid low water distribution coefficients. So, this work was conduct to test four techniques: (I) control (filtration), (II) chlorination, (III) compressed air, and (IV) chlorination and compressed air. The best result was obtained with $0.5 \mathrm{mg} \mathrm{L}^{-1}$ free chlorine residual and self-compensating dripper.
\end{abstract}

KEYWORDS: drip irrigation system, emitter clogging, effluent.

\section{INTRODUÇÃO}

O crescimento da população mundial e da atividade humana tem contribuído para o aumento no consumo de água e alimentos. Considerando que menos de $1 \%$ do volume total de água está em rios e lagos (LAR \& STEWART, 1994) e que a poluição dos mesmos tem sido um fator importante de redução da disponibilidade de uso potável, verifica-se que a água é um recurso natural cada vez mais escasso. Isso força ao uso de águas de fontes alternativas que possam ser econômica e efetivamente utilizadas. PESCOD (1992) indica o uso de efluente de estações de tratamento de esgoto (água residuária) na agricultura. BASTOS (1999) destaca o controle de poluição, a economia de água e fertilizantes, a reciclagem de nutrientes e o aumento de produção agrícola pela adoção dessa prática. Assim, a irrigação com o uso desse tipo de água é interessante do ponto de vista ambiental e também agronômico.

Um dos sistemas mais apropriados e em notável expansão é o sistema de irrigação por gotejamento, o qual apresenta vantagens, como a economia de água e energia, possibilidade de automação e fertirrigação (SCALOPPI, 1986). Estabelecendo como critério de seleção a qualidade da água, a irrigação por gotejamento constitui um dos sistemas que apresenta menores riscos de

\footnotetext{
${ }^{1}$ Extraído da tese de doutorado do primeiro autor.

2 Engo Agrônomo, Doutorando, Escola Superior de Agricultura "Luiz de Queiroz”, ESALQ/USP, Piracicaba - SP, Fone: (0XX19) 3429.4218 - R: 261/255, deniscesar@ yahoo.com.br

${ }^{3}$ Eng ${ }^{\circ}$ Agrícola, Prof. Adjunto, Departamento de Engenharia Rural, ESALQ/USP, Piracicaba - SP.

Recebido pelo Conselho Editorial em: 28-9-2004
}

Aprovado pelo Conselho Editorial em: 3-1-2007 
contaminação (AYERS \& WESTCOT, 1999), porque existe menor contato do irrigante e da parte aérea das plantas com o efluente.

Entretanto, esse sistema de irrigação tem como principais limitações o fato de seus emissores serem bastante suscetíveis ao entupimento, em diferentes níveis, de acordo com a seção mínima de passagem de água pelo labirinto e outras características intrínsecas ao modelo de gotejador descritas por LOPEZ et al. (1997). O entupimento é agravado pelo uso de águas residuárias, reduzindo a uniformidade de aplicação e de distribuição da água devido aos elevados teores de sólidos em suspensão e bactérias formadoras de biofilme (GILBERT et al., 1982; CHANDRAKANTH et al., 1988; BASTOS, 1999), aumentando os custos operacionais e necessitando de checagem, troca e recuperação de emissores com mau funcionamento (BUCKS et al., 1979).

Para a minimização do entupimento, são sugeridas diversas técnicas na literatura. Entre as práticas mais usuais, estão a filtragem e a cloração (NAKAYAMA \& BUCKS, 1991). Segundo ADIN \& SACKS (1991), a filtragem é absolutamente essencial e previne o entupimento imediato por partículas relativamente grandes e com formas irregulares, ao passo que a modificação interna dos emissores e o pré-tratamento com oxidantes e floculantes reduz a possibilidade de ocorrência do entupimento.

Como exemplo de estudo relacionado a essas técnicas, cita-se o trabalho de TAJRISHY et al. (1994), os quais observaram que a adequada filtragem do efluente oriundo de tratamento secundário reduz a necessidade de cloração freqüente e de lavagem da linha lateral. Os mesmos autores verificaram similaridade entre a cloração intermitente com $2 \mathrm{mg} \mathrm{L}^{-1}$ de cloro residual livre durante a última hora do ciclo de irrigação e a cloração contínua com $0,4 \mathrm{mg} \mathrm{L}^{-1}$ de cloro residual livre, quanto à eficiência na prevenção da formação de biofilme nos emissores e na rede distribuidora.

Contudo, o uso de águas residuárias oriundas de estações de tratamento de esgoto doméstico nos sistemas de irrigação é incipiente no Brasil e requer estudos. As medidas combinadas e adotadas para a solução do problema em questão devem ser eficientes, com custo acessível ao produtor irrigante, apresentar baixo risco à saúde humana e não causar danos às plantas cultivadas e ao ambiente. Além disso, também deve ser considerada a criação de novas tecnologias de prevenção ao entupimento, tais como a aplicação de ar comprimido, como sugerido por WATANABE \& METSUGI (1979) e KELLER \& BLIESNER (1990).

Considerando esses aspectos, neste trabalho, teve-se por objetivo selecionar manejo e modelo de gotejador para a minimização do entupimento em sistemas de irrigação por gotejamento com água residuária oriunda do tratamento secundário de esgoto doméstico.

\section{MATERIAL E MÉTODOS}

Este trabalho foi conduzido em área da Escola Superior de Agricultura "Luiz de Queiroz" (ESALQ), pertencente à Universidade de São Paulo (USP), sob delineamento em parcelas subdivididas, constando de uma unidade experimental com quatro parcelas e três subparcelas.

Testaram-se quatro manejos para minimizar o entupimento de gotejadores: (I) controle (somente filtragem), (II) cloração com filtragem do efluente, (III) ar comprimido com filtragem do efluente e (IV) cloração e ar comprimido, com filtragem do efluente. Para isso, utilizaram-se quatro modelos de gotejadores (A, B, C e D) previamente selecionados por disponibilidade comercial, grau de entupimento, coeficiente de variação, probabilidade de encontrar emissores na faixa de $\pm 5 \%$ de variação em relação à vazão original, ou seja, próximos ao desempenho quando novos, e demais características apresentadas na Tabela 1.

Todos os manejos tiveram filtragem composta de filtro de areia com diâmetro efetivo da areia igual a $0,59 \mathrm{~mm}$, filtro de disco de 120 mesh e filtro de tela de 200 mesh. O sistema era retrolavado a cada irrigação ou quando a perda de pressão atingia $6 \mathrm{kPa}$. 
TABELA 1. Características dos modelos de emissores utilizados e tubulação gotejadora correspondente.

\begin{tabular}{|c|c|c|c|c|c|c|c|c|c|c|}
\hline Emissor & \multicolumn{3}{|c|}{$\begin{array}{l}\text { Autocompensante e com } \\
\text { Membrana Autolimpante }\end{array}$} & \multicolumn{2}{|c|}{$\begin{array}{l}\text { Forma do } \\
\text { Emissor }\end{array}$} & $\begin{array}{l}\mathrm{L}_{\text {labirinto }} \\
(\mathrm{mm})\end{array}$ & $\begin{array}{l}S_{\text {labirinto }} \\
(\mathrm{mm})\end{array}$ & $\begin{array}{l}\mathrm{D}_{\text {tubulação }} \\
(\mathrm{mm})\end{array}$ & $\begin{array}{l}\text { E }_{\text {tubulação }} \\
(\mathrm{mm})\end{array}$ & $\begin{array}{c}E_{\text {emissor }} \\
(\mathrm{cm})\end{array}$ \\
\hline A & & não & & plan & & 175 & 0,8 & 16,0 & 0,45 & 20 \\
\hline B & & não & & cilínd & & 170 & 1,0 & 12,0 & 1,00 & 50 \\
\hline $\mathrm{C}$ & & não & & cilínd & & 200 & 1,0 & 13,8 & 1,00 & 40 \\
\hline $\mathrm{D}$ & & $\operatorname{sim}$ & & plan & & 30 & 1,0 & 14,2 & 0,90 & 75 \\
\hline Emissor & $\begin{array}{l}\text { qinicial } \\
\left(\mathrm{L} \mathrm{h}^{-1}\right) \\
\end{array}$ & $\begin{array}{l}\mathrm{CV}_{\mathrm{f}} \\
(\%) \\
\end{array}$ & $\begin{array}{l}\text { UD } \\
(\%)\end{array}$ & $\begin{array}{l}\mathrm{CV}_{373} \\
(\%)\end{array}$ & $\begin{array}{c}\mathrm{GE}_{373} \\
(\%)\end{array}$ & $\begin{array}{l}\mathrm{P}_{373} \\
(\%)\end{array}$ & K & X & & \\
\hline A & 0,89 & 2,4 & 92,5 & 22,6 & $>10$ & 25 & 0,0616 & 0,5747 & & \\
\hline B & 1,61 & 4,9 & 85,7 & 28,0 & $>10$ & 27 & 0,1209 & 0,5548 & & \\
\hline $\mathrm{C}$ & 2,61 & 10,3 & 76,3 & 9,8 & $<5$ & 45 & 0,1357 & 0,6466 & 0,9 & \\
\hline D & 1,61 & 1,7 & 94,9 & 7,0 & $<5$ & 45 & 1,6322 & $-0,0003$ & 0,9 & \\
\hline
\end{tabular}

$\mathrm{L}_{\text {labirinto }}=$ comprimento da passagem de água pelo labirinto no emissor; $S_{\text {labirinto }}=$ dimensão mais estreita da passagem de água pelo labirinto no emissor; $\mathrm{D}_{\text {tubulação }}=$ diâmetro da tubulação; $\mathrm{E}_{\text {tubulação }}=$ espessura da tubulação; $\mathrm{E}_{\text {emissor }}=$ espaçamento entre emissores; $\mathrm{q}_{\text {inicial }}=$ vazão inicial; $\mathrm{CV}_{\mathrm{f}}=$ coeficiente de variação de fabricação; $U D=$ uniformidade de distribuição; $\mathrm{CV}_{373}=$ coeficiente de variação em $373 \mathrm{~h}$ de uso contínuo com a água residuária utilizada; $\mathrm{GE}_{373}=$ grau de entupimento em $373 \mathrm{~h}$ de uso contínuo; $\mathrm{P}_{373}=$ probabilidade de encontrar emissores com variação inferior a 5\% em relação ao gotejador novo após $373 \mathrm{~h}$ de uso; $\mathrm{K}$ e $\mathrm{X}=$ coeficientes da equação do emissor (obs.: para o autocompensante, é linear); e $\mathrm{R}^{2}=$ coeficiente de correlação da equação do emissor. Equação do emissor: $\mathrm{q}=\mathrm{K} \mathrm{H}^{\mathrm{x}}$

A cloração foi realizada a cada irrigação com o uso de hipoclorito de sódio, de forma a atingir $0,5 \mathrm{mg} \mathrm{L}^{-1}$ de cloro residual livre no último gotejador do sistema após 15 minutos de reação e transporte. A solução era aplicada ao final de cada irrigação, e a solução permanecia na tubulação gotejadora durante 24 horas. Em seguida, a água era drenada para a aplicação do ar comprimido.

$\mathrm{O}$ ar foi injetado por uso de compressor de forma a atingir $1,96 \mathrm{kPa}$ na entrada dos gotejadores, quando não se irrigava, em nove operações diárias durante 30 minutos cada. $\mathrm{O}$ compressor possuía vazão igual a $2 \mathrm{~L} \mathrm{~s}^{-1}$ e pressão igual a $275 \mathrm{kPa}$. A vazão do compressor foi distribuída para os 75 gotejadores de cada modelo por manejo considerado (III e IV), e a pressão foi utilizada em grande parte para superar o desnível geométrico e as perdas de carga no sistema.

O manejo IV compreendeu a combinação da cloração após as irrigações e do ar comprimido entre as irrigações depois de drenada a água presente nas tubulações adutoras, distribuidoras e laterais.

Os valores de $\mathrm{q}_{\text {inicial }}, \mathrm{CV}_{\mathrm{f}}$ e UD foram calculados aplicando-se as eqs.(1) a (3). Os valores a $373 \mathrm{~h}$ de aplicação de água residuária foram calculados aplicando-se as eqs.(4) e (5), e são provenientes de teste preliminar utilizando sistema de filtragem e água similares durante 12 horas dia $^{-1}$, auxiliando na caracterização dos modelos quanto ao potencial de entupimento.

A cultura irrigada foi a tangerina com espaçamento de 6 x $4 \mathrm{~m}$, em nível. O método utilizado para o manejo da irrigação foi o balanço hídrico diário [eq.(6)], baseado na evaporação do tanque Classe "A", cujas constantes foram: $\mathrm{Kp}=0,85 ; \mathrm{Kc}=0,9 ; \mathrm{Kr}=0,35$, descritas por DOORENBOS \& PRUITT (1997), e disponibilidade real de água no solo igual a $20,5 \mathrm{~mm}$. A qualidade do efluente utilizado está descrita na Tabela 2.

O tempo de irrigação foi calculado como mostrado na eq.(7), considerando a eficiência de aplicação de água de irrigação igual a 90\%. Além desses fatores, a irrigação somente era realizada após ser completado o mínimo de 15 minutos para transporte e reação da solução clorada com a água na tubulação, somados aos dois a cinco minutos para injeção da mesma, como era o caso dos manejos II e IV, porém padronizou-se o mesmo tempo de irrigação para todos os manejos.

Efetuaram-se três avaliações de vazão, coletando-se água de 75 gotejadores por modelo a cada manejo, durante cinco minutos. Essas avaliações foram realizadas a 34; 58 e 67 horas de irrigação. Para o cálculo das vazões, foi utilizada a eq.(1). 
TABELA 2. Características físico-químicas do efluente utilizado.

\begin{tabular}{cccc}
\hline Parâmetro & Unidade & Concentração & Desvio-Padrão \\
\hline Demanda bioquímica de oxigênio & $\mathrm{g} \mathrm{m}^{-3}$ & 20 & 6,3 \\
Demanda química de oxigênio & $\mathrm{g} \mathrm{m}^{-3}$ & 77 & 13,2 \\
Sólidos totais & $\mathrm{g} \mathrm{m}^{-3}$ & 314 & 11,6 \\
Sólidos suspensos & $\mathrm{g} \mathrm{m}^{-3}$ & 23 & 8,2 \\
Sólidos dissolvidos & $\mathrm{g} \mathrm{m}^{-3}$ & 291 & 5,4 \\
Amônio & $\mathrm{g} \mathrm{m}^{-3}$ & 0,6 & 0,5 \\
Nitrato & $\mathrm{g} \mathrm{m}^{-3}$ & 23,3 & 6,8 \\
Fósforo & $\mathrm{g} \mathrm{m}^{-3}$ & 2,0 & 1,2 \\
Potássio & $\mathrm{g} \mathrm{m}^{-3}$ & 9,3 & 1,2 \\
Cálcio & $\mathrm{g} \mathrm{m}^{-3}$ & 23,8 & 1,9 \\
Magnésio & $\mathrm{g} \mathrm{m}^{-3}$ & 6,4 & 1,0 \\
Sódio & $\mathrm{g} \mathrm{m}^{-3}$ & 34 & 3,6 \\
Sulfato & $\mathrm{g} \mathrm{m}^{-3}$ & 48 & 5,4 \\
Ferro & $\mathrm{g} \mathrm{m}^{-3}$ & 0,05 & 0,02 \\
Manganês & $\mathrm{g} \mathrm{m}^{-3}$ & 0,05 & 0,02 \\
Coliformes totais & $\mathrm{NMP} / 100 \mathrm{~mL}$ & $5,4610^{4}$ & $2,1910^{4}$ \\
Coliformes fecais & $\mathrm{NMP} / 100 \mathrm{~mL}$ & $2,3010^{4}$ & $1,7710^{4}$ \\
Turbidez & $\mathrm{UTN}$ & 39,3 & 11,6 \\
pH & - & 7,3 & 0,4 \\
\hline
\end{tabular}

Utilizando os dados das avaliações mencionadas, calcularam-se o coeficiente de variação de vazão [eq.(4)], o grau de entupimento [eq.(5)] e a probabilidade de encontrar emissores na faixa de $\pm 5 \%$ de variação em relação à vazão inicial, ou seja, gotejadores com desempenho próximo ao desempenho quando novos.

Efetuaram-se análises estatísticas, tais como o teste $\mathrm{F}$ e o de comparação de médias por Tukey, a $5 \%$ e a $1 \%$ de significância para os coeficientes de variação de vazão e graus de entupimento. Também se efetuou a análise de regressão para grau de entupimento em função do tempo.

$\mathrm{Na}$ análise da distribuição dos dados de variação de vazão, anteriormente ao teste $\mathrm{F}$, verificou-se que os mesmos não seguiam distribuição normal. Assim, foi necessário efetuar a transformação dos dados pelo cálculo do logaritmo na base neperiana dos valores dos coeficientes de variação de vazão e, posteriormente, proceder à análise de variância e ao teste de comparação de médias com os dados transformados.

$$
q=\frac{V}{1000 t} 60
$$

em que,

q - vazão do gotejador, $\mathrm{L} \mathrm{h}^{-1}$;

$\mathrm{V}$ - volume de água coletada, $\mathrm{mL}, \mathrm{e}$

$\mathrm{t}$ - tempo de coleta de água, min.

$$
\mathrm{CV}_{\mathrm{f}}=\frac{\mathrm{s}_{\text {inicial }}}{\mathrm{q}_{\text {inicial }}} 100
$$

em que,

$\mathrm{CV}_{\mathrm{f}}$ - coeficiente de variação de vazão de fabricação, \%;

$s_{\text {inicial }}$ - desvio-padrão da vazão dos gotejadores quando novos, $\mathrm{L} \mathrm{h}^{-1}$, e

$\mathrm{q}_{\text {inicial }}$ - vazão média dos gotejadores quando novos, $\mathrm{L} \mathrm{h}^{-1}$. 


$$
\mathrm{UD}=\frac{\mathrm{q}_{25 \%}}{\mathrm{q}_{\text {média }}} 100
$$

em que,

UD - uniformidade de distribuição, \%;

$\mathrm{q}_{25} \%$ - vazão média de $1 / 4$ dos menores valores, $\mathrm{L} \mathrm{h}^{-1}$, e

qmédia - vazão média, $\mathrm{L} \mathrm{h}^{-1}$.

$$
\mathrm{CV}_{\mathrm{q}}=\frac{{ }^{\mathrm{s}} \text { usado }}{\mathrm{q}_{\text {usado }}} 100
$$

em que,

$\mathrm{CV}_{\mathrm{q}}$ - coeficiente de variação de uso dos gotejadores, \%;

$\mathrm{s}_{\text {usado }}$ - desvio-padrão da vazão dos gotejadores quando usados, $\mathrm{L} \mathrm{h}^{-1}$, e

$\mathrm{q}_{\text {usado }}$ - vazão média dos gotejadores quando usados, $\mathrm{L} \mathrm{h}^{-1}$.

$$
\mathrm{GE}=\left(1-\frac{\mathrm{q}_{\text {usado }}}{\mathrm{q}_{\text {inicial }}}\right) 100
$$

em que,

GE - grau de entupimento, $\%$.

$$
\mathrm{ET}_{\mathrm{c}}=\mathrm{Ev} \mathrm{K}_{\mathrm{p}} \mathrm{K}_{\mathrm{c}} \mathrm{K}_{\mathrm{r}}
$$

em que,

$\mathrm{ET}_{\mathrm{c}}$ - evapotranspiração da cultura, $\mathrm{mm} \mathrm{dia}^{-1}$;

Ev - evaporação no tanque Classe "A", $\mathrm{mm} \mathrm{dia}^{-1}$;

$\mathrm{K}_{\mathrm{p}}$ - coeficiente do tanque Classe "A", adimensional;

$\mathrm{K}_{\mathrm{c}}$ - coeficiente da cultura, adimensional, e

$\mathrm{K}_{\mathrm{r}}$ - coeficiente de redução para irrigação localizada.

$$
\mathrm{T}_{\mathrm{i}}=\frac{\sum \mathrm{ET}_{\mathrm{C}} \mathrm{S}_{1} \mathrm{~L}}{\mathrm{q}_{\text {média }} \mathrm{n}_{1} \mathrm{~g}_{1}} 60 \mathrm{E}_{\mathrm{i}}^{-1}
$$

em que,

Ti - tempo de irrigação, min;

$\mathrm{S}_{1}$ - espaçamento entre duas linhas gotejadoras, $\mathrm{m}$;

$\mathrm{L}$ - comprimento da parcela correspondente a um manejo, $\mathrm{m}$;

$\mathrm{n}_{1}$ - número de linhas gotejadoras em um manejo, adimensional;

$\mathrm{g}_{1}$ - número de gotejadores por linha de irrigação, e

$\mathrm{E}_{\mathrm{i}}$ - eficiência de aplicação de água de irrigação, adimensional.

\section{RESULTADOS E DISCUSSÃO}

$\mathrm{Na}$ Tabela 3, apresentam-se os valores médios do coeficiente de variação de uso dos gotejadores nas diferentes épocas de avaliação de vazão. Os resultados obtidos a partir dessa tabela mostram que, independentemente do manejo utilizado, o coeficiente não varia estatisticamente. Isso indica que, dentre os manejos utilizados, quanto ao coeficiente de variação, qualquer tratamento apresentaria o mesmo resultado; contudo, o uso apenas de filtragem seria mais indicado, pois não requer custos adicionais, como os provenientes da adição de cloro ou de ar comprimido.

Pela Tabela 3, observa-se que, a partir do tempo de irrigação de 58 h, os coeficientes de variação de uso apresentam-se superiores a $10 \%$ na maioria dos valores analisados e para todos os manejos, o que indicaria que nenhum tratamento foi eficiente em manter os coeficientes no nível desejável em relação aos tratamentos testados. A precipitação pluviométrica (418 mm de fevereiro a agosto de 2003) e a pequena evaporação da água no tanque Classe "A" (média de 3,06 mm dia ${ }^{-1}$ ) conduziram a intervalos de irrigação que podem ter favorecido o crescimento bacteriano, conseqüentemente, o elevado coeficiente de variação de uso. 
TABELA 3. Coeficientes de variação de uso (\%) em diferentes modelos de gotejador e manejo após a irrigação com água residuária para três avaliações de vazão.

\begin{tabular}{ccrrr}
\hline \multirow{2}{*}{ Modelo de Gotejador } & \multirow{2}{*}{ Tipo de Manejo } & \multicolumn{3}{c}{ Tempo Irrigado (horas) } \\
\cline { 3 - 5 } & Controle & 44 & \multicolumn{1}{c}{58} & \multicolumn{1}{c}{67} \\
\hline \multirow{2}{*}{ A } & Cloração & $21,75 \mathrm{a}$ & $28,77 \mathrm{a}$ \\
& Ar comprimido & $6,84 \mathrm{a}$ & $9,69 \mathrm{a}$ & $8,88 \mathrm{a}$ \\
& Cloração e ar comprimido & $8,08 \mathrm{a}$ & $12,18 \mathrm{a}$ & $18,84 \mathrm{a}$ \\
& Controle & $8,49 \mathrm{a}$ & $10,22 \mathrm{a}$ & $7,01 \mathrm{a}$ \\
\hline \multirow{2}{*}{$\mathrm{B}$} & Cloração & $5,97 \mathrm{a}$ & $10,61 \mathrm{a}$ & $11,36 \mathrm{a}$ \\
& Ar comprimido & $5,35 \mathrm{a}$ & $15,88 \mathrm{a}$ & $17,58 \mathrm{a}$ \\
& Cloração e ar comprimido & $7,16 \mathrm{a}$ & $23,07 \mathrm{a}$ & $30,99 \mathrm{a}$ \\
\hline & Controle & $6,84 \mathrm{a}$ & $11,35 \mathrm{a}$ & $12,69 \mathrm{a}$ \\
C & Cloração & $7,36 \mathrm{a}$ & $24,96 \mathrm{a}$ & $17,65 \mathrm{a}$ \\
& Ar comprimido & $5,76 \mathrm{a}$ & $20,34 \mathrm{a}$ & $22,29 \mathrm{a}$ \\
& Cloração e ar comprimido & $10,21 \mathrm{a}$ & $17,03 \mathrm{a}$ & $13,87 \mathrm{a}$ \\
\hline & Controle & $11,43 \mathrm{a}$ & $21,97 \mathrm{a}$ & $21,80 \mathrm{a}$ \\
& Cloração & $4,64 \mathrm{a}$ & $7,99 \mathrm{a}$ & $12,96 \mathrm{a}$ \\
& Ar comprimido & $6,20 \mathrm{a}$ & $12,15 \mathrm{a}$ & $12,64 \mathrm{a}$ \\
& Cloração e ar comprimido & $4,22 \mathrm{a}$ & $12,47 \mathrm{a}$ & $17,89 \mathrm{a}$ \\
\hline
\end{tabular}

Médias com mesma letra entre linhas, no mesmo modelo de gotejador, são iguais estatisticamente, pelo teste de Tukey, a $5 \%$ de significância.

$\mathrm{Na}$ Tabela 4, apresentam-se os valores médios do grau de entupimento dos gotejadores. Os resultados obtidos a partir dessa tabela mostram que os manejos diferiram estatisticamente entre si apenas para o modelo $\mathrm{C}$ às $58 \mathrm{~h}$, destacando-se a cloração com maior grau de entupimento, porém não diferindo do controle. Valores negativos indicariam aumento de vazão; contudo, estatisticamente, isso não é comprovado.

TABELA 4. Graus de entupimento (\%) em diferentes tipos de manejo versus modelos de gotejador após a irrigação com água residuária para três avaliações de vazão.

\begin{tabular}{ccrrr}
\hline \multirow{2}{*}{ Modelo de Gotejador } & \multirow{2}{*}{ Tipo de Manejo } & \multicolumn{3}{c}{ Tempo Irrigado (horas) } \\
\cline { 3 - 5 } & & 34 & \multicolumn{1}{c}{58} & \multicolumn{1}{c}{67} \\
\hline \multirow{2}{*}{ A } & Controle & $3,19 \mathrm{a}$ & $4,32 \mathrm{a}$ & $5,47 \mathrm{a}$ \\
& Cloração & $7,98 \mathrm{a}$ & $1,03 \mathrm{a}$ & $-0,39 \mathrm{a}$ \\
& Ar comprimido & $5,76 \mathrm{a}$ & $-4,93 \mathrm{a}$ & $4,17 \mathrm{a}$ \\
& Cloração e ar comprimido & $4,83 \mathrm{a}$ & $-2,11 \mathrm{a}$ & $-5,18 \mathrm{a}$ \\
\hline \multirow{2}{*}{$\mathrm{B}$} & Controle & $8,79 \mathrm{a}$ & $5,48 \mathrm{a}$ & $6,43 \mathrm{a}$ \\
& Cloração & $11,98 \mathrm{a}$ & $3,81 \mathrm{a}$ & $-4,65 \mathrm{a}$ \\
& Ar comprimido & $7,06 \mathrm{a}$ & $-3,71 \mathrm{a}$ & $1,33 \mathrm{a}$ \\
& Cloração e ar comprimido & $3,84 \mathrm{a}$ & $0,14 \mathrm{a}$ & $5,62 \mathrm{a}$ \\
\hline \multirow{2}{*}{ C } & Controle & $12,69 \mathrm{a}$ & $10,44 \mathrm{ab}$ & $7,54 \mathrm{a}$ \\
& Cloração & $18,12 \mathrm{a}$ & $17,43 \mathrm{a}$ & $8,14 \mathrm{a}$ \\
& Ar comprimido & $14,32 \mathrm{a}$ & $6,97 \mathrm{~b}$ & $11,48 \mathrm{a}$ \\
& Cloração e ar comprimido & $17,52 \mathrm{a}$ & $5,43 \mathrm{~b}$ & $10,37 \mathrm{a}$ \\
\hline & Controle & $3,40 \mathrm{a}$ & $7,89 \mathrm{a}$ & $1,86 \mathrm{a}$ \\
& Cloração & $6,27 \mathrm{a}$ & $1,50 \mathrm{a}$ & $0,89 \mathrm{a}$ \\
& Ar comprimido & $4,81 \mathrm{a}$ & $6,49 \mathrm{a}$ & $3,16 \mathrm{a}$ \\
& Cloração e ar comprimido & $5,27 \mathrm{a}$ & $6,30 \mathrm{a}$ & $4,67 \mathrm{a}$ \\
\hline
\end{tabular}

Médias com mesma letra entre linhas, no mesmo modelo de gotejador, são iguais estatisticamente, pelo teste de Tukey, a $5 \%$ de significância. 
Os valores de grau de entupimento superiores a $5 \%$ (possivelmente devido ao fato de os filtros permitirem a passagem de sólidos dissolvidos, de enxofre e de bactérias formadoras de mucilagem para tubulação e emissores) encontrados nos gotejadores não-autocompensantes do manejo-controle, indicam que, pelo menos, esses precisam de tratamentos complementares. No caso de uso de somente filtragem, seria aconselhável adotar o modelo autolimpante $\mathrm{D}$, pois esse apresentou, aparentemente, o menor valor médio para o grau de entupimento $(1,86 \%)$ às $67 \mathrm{~h}$ de irrigação.

Com exceção do modelo $\mathrm{C}$, aparentemente, notam-se menores graus de entupimento aplicando-se a solução clorada. Isso poderia ser motivo para estudar doses que proporcionem maiores níveis de cloro residual livre ao final do sistema, ou seja, superior a $0,5 \mathrm{mg} \mathrm{L}^{-1}$, porém não atingindo valores tal como o de $300 \mathrm{mg} \mathrm{L}^{-1}$ encontrado no trabalho de RESENDE (1999), que é recomendado apenas para recuperação de emissores. A redução do $\mathrm{pH}$ por adição de ácidos e a aplicação anterior ao sistema de filtragem poderiam também auxiliar na prevenção mais eficiente ao entupimento dos emissores.

Os manejos com ar comprimido não se mostraram eficientes na minimização do grau de entupimento. Possivelmente, a baixa pressão de ar (1,96 kPa) não foi suficiente para expelir partículas, e a vazão de ar (máximo de $1 \mathrm{~L} \mathrm{~s}^{-1}$ por manejo) não foi suficiente para secar totalmente as adutoras e tubulações secundárias, permitindo a formação da mucilagem que foi observada visualmente. Contudo, em certos momentos, nos gotejadores não-autocompensantes, ocorreram aparentes reduções no grau de entupimento, particularmente da primeira para a segunda avaliação.

Dos valores obtidos da análise de probabilidade e apresentados na Tabela 5, nota-se que a maior probabilidade de se ter emissores na faixa aceitável de $\pm 5 \%$ em relação aos mesmos quando novos, encontra-se na combinação do modelo de gotejador D com a técnica de cloração. Isso indica que as características intrínsecas a esse emissor, tais como a característica autocompensante associada ao formato desse modelo, são mais apropriadas ao uso de água residuária, e a minimização do entupimento é potencializada pela cloração na limpeza do biofilme obstrutor.

Os modelos A e B tiveram baixo desempenho, com menos de $50 \%$ de probabilidade de encontrar emissores na faixa aceitável. $O$ uso de cloração com filtragem permite melhores resultados para o modelo $\mathrm{A}$, a $58 \mathrm{~h}$ e a $67 \mathrm{~h}$ de irrigação. $\mathrm{O}$ uso de ar comprimido ou esse combinado com a cloração reduziu a probabilidade considerada, o que indica não ser recomendada a utilização desse tratamento para o modelo A. A cloração e a aplicação do ar comprimido, isoladamente, auxiliaram na minimização do entupimento no modelo $\mathrm{B}$, com mais de $50 \%$ de emissores, com menos de 5\% de variação. Por outro lado, o efeito combinado de cloro e ar não é aconselhável, pois menos emissores se apresentam na faixa de variação aceitável, em relação ao tratamento realizado apenas com filtragem. $\mathrm{O}$ modelo $\mathrm{C}$ apresentou bons resultados apenas às $58 \mathrm{~h}$ para os tratamentos com ar comprimido.

Para o modelo A, é recomendável o uso de cloração isoladamente. Para o modelo C, não é recomendável o uso do ar comprimido. Para o modelo $\mathrm{B}$, não é interessante a combinação de ar comprimido e cloração.

Os resultados obtidos na Tabela 6 indicam que há influência da cloração ao longo do tempo para modelos de gotejador não-autocompensantes, embora o modelo $\mathrm{C}$ ainda apresente entupimento de $8,14 \%$ a 67 h. Como explicação auxiliar ao fato dessa recuperação de emissores têm-se que entupimentos iniciais, anteriormente aos 20 dias de início do experimento (tempo utilizado no ajuste das metodologias) podem ter ocorrido, originando os valores de grau de entupimento observados na primeira avaliação de vazão. Portanto, além de caráter preventivo, percebe-se que alguns tratamentos, como a cloração, mesmo à baixa concentração, podem ter efeitos de recuperação após certo período, como observado pela tendência de redução do grau de entupimento no modelo matemático linear apresentado. Possivelmente, concentrações superiores de solução clorada também possibilitem melhor efeito na minimização de entupimento nesses emissores. 
TABELA 5. Probabilidades (\%) de encontrar gotejadores com vazão na faixa de variação de $\pm 5 \%$ em relação à vazão média dos mesmos quando novos, após a irrigação com água residuária, para três avaliações de vazão.

\begin{tabular}{ccrcc}
\hline \multirow{2}{*}{ Tipo de Manejo } & Modelo de & \multicolumn{3}{c}{ Tempo Irrigado (horas) } \\
\cline { 2 - 5 } Gotejador & 34 & 58 & 67 \\
& $\mathrm{~A}$ & 55 & 40 & 38 \\
Controle & $\mathrm{B}$ & 20 & 45 & 48 \\
& $\mathrm{C}$ & 5 & 30 & 56 \\
& $\mathrm{D}$ & 65 & 45 & 60 \\
\hline \multirow{3}{*}{ Cloração } & $\mathrm{A}$ & 45 & 70 & 60 \\
& $\mathrm{~B}$ & 15 & 57 & 53 \\
& $\mathrm{C}$ & 0 & 16 & 55 \\
& $\mathrm{D}$ & 50 & 83 & 73 \\
Ar comprimido & $\mathrm{A}$ & 61 & 34 & 35 \\
& $\mathrm{~B}$ & 30 & 40 & 58 \\
& $\mathrm{C}$ & 1 & 68 & 49 \\
& $\mathrm{D}$ & 60 & 65 & 62 \\
\hline \multirow{3}{*}{ Cloração e ar } & $\mathrm{A}$ & 20 & 28 & 34 \\
comprimido & $\mathrm{B}$ & 22 & 27 & 43 \\
& $\mathrm{C}$ & 3 & 75 & 54 \\
\hline
\end{tabular}

TABELA 6. Resultado da análise de regressão para grau de entupimento (GE), em função do período em que o experimento foi conduzido $(\mathrm{t})$.

\begin{tabular}{|c|c|c|}
\hline Tipo de Manejo & Modelo de Gotejador & $\begin{array}{c}\mathrm{GE}=\mathrm{at}+\mathrm{b} \\
\mathrm{GE}(\%) \text { e t (dias) }\end{array}$ \\
\hline \multirow{4}{*}{ Controle } & $\mathrm{A}$ & $+0,0136 \mathrm{t}+2,3152 \mathrm{NS}$ \\
\hline & B & $-0,0148 t+9,081 \quad N S$ \\
\hline & $\mathrm{C}$ & $-0,0307 \mathrm{t}+14,751 \mathrm{NS}$ \\
\hline & $\mathrm{D}$ & $-0,0076 \mathrm{t}+5,5064 \mathrm{NS}$ \\
\hline \multirow{4}{*}{ Cloração } & $\mathrm{A}$ & $-0,0509 \mathrm{t}+10,387 \quad * *$ \\
\hline & B & $-0,0993 t+18,38$ \\
\hline & $\mathrm{C}$ & $-0,0583 \mathrm{t}+23,167 \quad *$ \\
\hline & $\mathrm{D}$ & $-0,0328 \mathrm{t}+7,7353 \mathrm{NS}$ \\
\hline \multirow{4}{*}{ Ar comprimido } & $\mathrm{A}$ & $-0,0126 t+3,5237 \mathrm{NS}$ \\
\hline & $\mathrm{B}$ & $-0,0367 t+6,9807 \mathrm{NS}$ \\
\hline & $\mathrm{C}$ & $-0,0188 \mathrm{t}+13,707 \mathrm{NS}$ \\
\hline & $\mathrm{D}$ & $-0,0091 \mathrm{t}+6,1581 \mathrm{NS}$ \\
\hline \multirow{4}{*}{ Cloração e ar comprimido } & A & $-0,0604 \mathrm{t}+8,0991 \quad *$ \\
\hline & B & $+0,0092 \mathrm{t}+1,8424 \mathrm{NS}$ \\
\hline & $\mathrm{C}$ & $-0,0454 \mathrm{t}+17,806 \mathrm{NS}$ \\
\hline & $\mathrm{D}$ & $-0,0031 \mathrm{t}+5,8788 \mathrm{NS}$ \\
\hline
\end{tabular}

NS - não-significativo estatisticamente; * - significativo a 5\%, pelo teste $\mathrm{F}$; ** - significativo a $1 \%$, pelo teste $\mathrm{F}$.

Pela Tabela 7, observa-se a probabilidade de encontrar emissores com mais de $50 \%$ de entupimento, bem como entupimento completo. Nota-se que, utilizando a cloração, há resistência ao entupimento, permanecendo menor percentagem de emissores com o problema. No entanto, quando associada à técnica de ar comprimido, o efeito não permanece, e certa oscilação de valores é constatada de um período para outro. Essa oscilação também foi observada por RAVINA et al. (1992). Quanto ao entupimento total, que não pode ultrapassar $10 \%$, o efeito mais positivo foi com cloração, estando ausente em alguns modelos de gotejador, após 67 h de irrigação. 
TABELA 7. Percentagem de emissores com vazão inferior à metade da vazão quando novos $\left(\mathrm{q}_{\text {usado }} \leq 0,5 \mathrm{q}_{\text {inicial }}\right)$ e completamente entupidos $(\mathrm{GE}=100 \%)$, após a irrigação com água residuária, para três avaliações de vazão.

\begin{tabular}{|c|c|c|c|c|c|c|c|}
\hline \multirow[t]{2}{*}{ Tipos de Manejo } & \multirow{2}{*}{$\begin{array}{l}\text { Modelos de } \\
\text { Gotejador }\end{array}$} & \multicolumn{3}{|c|}{$\begin{array}{c}\mathrm{q}_{\text {usado }} \leq 0,5 \mathrm{q}_{\text {novo }} \\
\text { Tempo Irrigado }(\mathrm{h})\end{array}$} & \multicolumn{3}{|c|}{$\begin{array}{c}\text { GE }=100 \% \\
\text { Tempo Irrigado }(\mathrm{h})\end{array}$} \\
\hline & & 34 & 58 & 67 & 34 & 58 & 67 \\
\hline \multirow{4}{*}{ Controle } & $\mathrm{A}$ & 0 & 1,33 & 5,33 & 0 & 1,33 & 1,33 \\
\hline & B & 0 & 1,33 & 6,67 & 0 & 0 & 1,33 \\
\hline & $\mathrm{C}$ & 0 & 2,67 & 1,33 & 0 & 0 & 1,33 \\
\hline & $\mathrm{D}$ & 1,33 & 5,33 & 2,67 & 1,33 & 1,33 & 1,33 \\
\hline \multirow{4}{*}{ Cloração } & A & 0 & 1,33 & 1,33 & 0 & 0 & 0 \\
\hline & $\mathrm{B}$ & 0 & 1,33 & 0 & 0 & 1,33 & 0 \\
\hline & $\mathrm{C}$ & 0 & 4 & 1,33 & 0 & 1,33 & 1,33 \\
\hline & $\mathrm{D}$ & 0 & 0 & 1,33 & 0 & 0 & 1,33 \\
\hline \multirow{4}{*}{ Ar comprimido } & $\mathrm{A}$ & 0 & 1,33 & 1,33 & 0 & 1,33 & 1,33 \\
\hline & B & 0 & 2,67 & 4 & 0 & 1,33 & 1,33 \\
\hline & $\mathrm{C}$ & 0 & 4 & 6,67 & 0 & 1,33 & 1,33 \\
\hline & $\mathrm{D}$ & 1,33 & 1,33 & 2,67 & 0 & 1,33 & 0 \\
\hline \multirow{4}{*}{$\begin{array}{l}\text { Cloração e ar } \\
\text { comprimido }\end{array}$} & $\mathrm{A}$ & 1,33 & 2,67 & 0 & 0 & 1,33 & 0 \\
\hline & B & 1,33 & 5,33 & 4 & 0 & 1,33 & 1,33 \\
\hline & $\mathrm{C}$ & 4 & 2,67 & 4 & 0 & 1,33 & 1,33 \\
\hline & D & 0 & 2,67 & 1,33 & 0 & 1,33 & 1,33 \\
\hline
\end{tabular}

\section{CONCLUSÕES}

Gotejador autocompensante associado à técnica de cloração é a melhor combinação para controle de entupimento de gotejadores aplicando água residuária. A cloração teve efeito positivo para gotejadores não-autocompensantes ao longo do tempo e foi o manejo que apresentou menor entupimento total. Por outro lado, os manejos com ar comprimido não foram eficientes, principalmente associados ao modelo de gotejador A (não-autocompensante, sem membrana autolimpante e com vazão inicial relativamente baixa).

\section{AGRADECIMENTOS}

À ESALQ/USP, pela estrutura e área experimental, e apoio de professores, funcionários, alunos de pós-graduação e alunos de graduação do grupo de pesquisa em irrigação e drenagem. À SEMAE, pelo efluente, energia elétrica e apoio de funcionários. À FAPESP, pelo apoio financeiro.

\section{REFERÊNCIAS}

ADIN, A.; SACKS, M. Dripper clogging factors in wastewater irrigation. Journal of Irrigation and Drainage Engineering, St. Joseph, v.117, n.6, p.813-26, 1991.

AYERS, R.S.; WESTCOT, D.W. A qualidade da água na agricultura. Tradução de GHEYI, H.R.; MEDEIROS, J.F. de; DAMASCENO, F.A.V. Campina Grande: UFPB, 1999. 218 p. (Estudos FAO: Irrigação e Drenagem, 29, Revisado 1).

BASTOS, R.K.X. Fertirrigação com águas residuárias. In: FOLEGATTI, M.V. (Coord.). Fertirrigação - cítrus, flores, hortaliças. Guaíba: Agropecuária, 1999. p.279-91.

BUCKS, D.A.; NAKAYAMA, F.S.; GILBERT, R.G. Trickle irrigation water quality and preventive maintenance. Agricultural Water Management, Amsterdam, v.2, p.149-62, 1979.

CHANDRAKANTH, M.S.; LAU, L.S.; WU, I.P. Plugging evaluation in reuse of primary wastewater effluent for drip irrigation. In: INTERNATIONAL MICRO-IRRIGATION CONGRESS, 4., 1988, Albury, Australia. Proceedings. 
DOORENBOS, J.; PRUITT, W.O. Necessidades hídricas das culturas. Tradução de GHEYI, H.R.; METRI, J.W.C.; DAMASCENO, F.A.V. Campina Grande: UFPB, 1997. 204 p. (Estudos FAO : Irrigação e Drenagem, 24).

GILBERT, R.G.; NAKAYAMA, F.S.; BUCKS, D.A.; FRENCH, O.F.; ADAMSON, K.C.; JOHNSON, R.M. Trickle irrigation: predominant bacteria in treated Colorado River water and biologically clogged emitters. Irrigation Science, Berlin, v.3, p.123-32, 1982.

KELLER, J.; BLIESNER, R.D. Sprinkle and Trickle Irrigation. New York: Van Nostrand Reinhold, 1990. 652 p.

LAR, R.; STEWART, B.A. Soil processes and water quality. London: Lewis Publishers, 1994. $398 \mathrm{p}$.

LOPEZ, R.J.; ABREU, J.M.H.; REGALADO, A.P.; HERNANDEZ, J.F.G. Riego localizado. $2^{\text {nd }}$. Mundi-Prensa : Madrid, 1997. 405 p.

NAKAYAMA, F.S.; BUCKS, D.A. Water quality in drip/trickle irrigation: A review. Irrigation Science, Berlin, v.12, p.187-92, 1991.

PESCOD, M.D. Wastewater treatment and use in agriculture. Rome: FAO, 1992.125 p. (Irrigation and Drainage Paper, 47).

RAVINA, I.; PAZ, E.; SOFER, Z.; MARCU, A.; SCHISCHA, A.; SAGI, G. Control of emitter clogging in drip irrigation with reclaimed wastewater. Irrigation Science, Berlin, v.13, p.129-39, 1992.

RESENDE, R.S. Suscetibilidade de gotejadores ao entupimento de causa biológica e avaliação do desentupimento via cloração da água de irrigação. 1999. 77 f. Dissertação (Mestrado em Irrigação e Drenagem) - Escola Superior de Agricultura "Luiz de Queiroz", Universidade de São Paulo, Piracicaba, 1999.

SCALOPPI, E.J. Características dos principais sistemas de irrigação. ITEM-Irrigação e Tecnologia Moderna, Brasília, n.25, p.22-7, 1986.

TAJRISHY, M A.; HILLS, D.J.; TCHOBANOGLOUS, G. Pretreatment of secundary effluent for drip irrigation. Journal of Irrigation and Drainage Engineering, Roston, v.120, n.4, 1994.

WATANABE, S.; METSUGI, M. Irrigation system. Official Gazette of the United States Patent Office, Washington, v.988, n.2, p.365, 1979. 